\title{
Sesame seeds essential oil and Sesamol modulate the pro-inflammatory function of macrophages and dendritic cells and promote Th2 response
}

\author{
Samaneh Khorrami ${ }^{1,2}$, Saeed Daneshmandi ${ }^{3}$, Ghasem Mosayebi*4,5 \\ Received: 02 Aug 2017 \\ Published: 10 Oct 2018
}

\begin{abstract}
Background: Herbal medicine is becoming progressively accepted treatment for management of different diseases worldwide. Recognition of the active ingredients and mechanisms of herbal medicine against the immune system and related anomalies is highly favorable. This experimental study aimed to investigate the effects of Sesame (Sesamum indicum L.) essential oil and sesamol as effective components on mouse splenocytes subsets, macrophages and dendritic cells (DCs).

Methods: Effective components of sesame were extracted and used to treat splenocytes, PHA $(5 \mu \mathrm{g} / \mathrm{ml})$ and LPS $(10 \mu \mathrm{g} / \mathrm{ml}) \mathrm{stimulated}$ splenocytes, macrophages and DCs in different concentration $(0.01-100 \mu \mathrm{g} / \mathrm{ml})$. The cell proliferation/viability was measured using the MTT assay and nitrite levels were measured by the diazotization method. Moreover, TNF- $\alpha$ and IL-1 $\beta$ cytokines concentration were assayed by ELISA. Treated DCs also analysed for maturation marker levels and cytokine production.

Results: Analysis of the results indicated that sesame components suppress PHA-stimulated splenocytes with no effect on LPS-stimulated subsets. Furthermore, the sesame ingredients reduced the release of IFN- $\gamma$ and increased secretion of IL-4 from lymphocytes. Macrophages viability was not affected and production of NO, TNF- $\alpha$, and IL- $1 \beta$ were inhibited using sesame essential oil and sesamol. DCs phenotype skewed to immature and release of TNF- $\alpha$ and IL-1 $\beta$ were abrogated form DCs.

Conclusion: These results indicate that sesame essential oil and its effective component as sesamol may capable of suppressing the response of cellular immunity with the domination of $\mathrm{Th} 2$ responses and also could modulate macrophages and the dendritic cells proinflammatory functions
\end{abstract}

Keywords: Sesame, Sesamol, Splenocyte, Macrophage, Nitric oxide, Dendritic cells

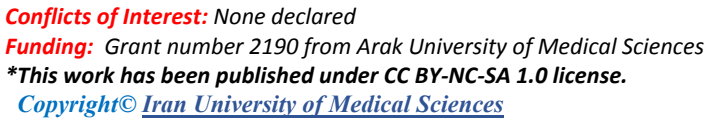

Cite this article as: Khorrami S, Daneshmandi S, Mosayebi Gh. Sesame seeds essential oil and Sesamol modulate the pro-inflammatory function of macrophages and dendritic cells and promote Th2 response. Med J Islam Repub Iran. 2018 (10 Oct);32:98. https://doi.org/10.14196/mjiri.32.98

\section{Introduction}

Generally, worldwide herbal medicines are widely used to manage various diseases

Identification of the active ingredients and mechanisms of herbal medicine against adverse immune reaction and related abnormalities are highly favourable (1). A wide variety of herbal extracts have been studied for their immunomodulatory effects on the lymphocytes and other immune cells in recent years (2). Considering the enormous variety of plant species, their potential in designing of new

\footnotetext{
*Corresponding author: Dr. Ghasem Mosayebi, ghasemmosayebi@arakmu.ac.ir

1. Department of Immunology, School of Medicine, Iran University of Medical Sciences, Tehran, Iran

2. Immunology Research Center, Institute of Immunology and Infectious disease, Iran University of Medical Sciences, Tehran, Iran

3. Department of Immunology, Faculty of Medical Sciences, Tarbiat Modares University, Tehran, Iran

4. Molecular and Medicine Research Center, Arak University of Medical Sciences, Arak, Iran

5. Traditional and Complementary Medicine Research Center (TCMRC), Arak University of Medical Sciences, Arak, Iran
}

medicines has not been completely discovered. So far, around 5000 species have been phytochemically examined, yet their pharmacological and biological attributes are vague. Sesame (Sesamum indicum L.) is an herbaceous annual plant of Pedaliaceae cultivated for its edible seed. It is originated from India and is now grown in many countries (e.g. Indian subcontinent, Mesopotamia, and Anatolia). In terms of nutrition, sesame seeds are rich in oil with high levels of unsaturated fatty acids, mainly oleic and

$\uparrow$ What is "already known" in this topic:

Sesame compounds have potential health benefits so that it can reduce the mechanisms of aging or malignancy and cardiovascular diseases.

\section{$\rightarrow$ What this article adds:}

Sesame essential oil and sesamol could modulate macrophages and the dendritic cells pro-inflammatory functions. Also, Sesame compounds can induce a TH2 immune response. 
linoleic, proteins, minerals, lignans, tocopherol, and phytosterol (3). Sesame (Sesamum indicum L.) seed is composed of $45 \%$ to $50 \%$ lipid, $5 \%$ to $6 \%$ moisture, $10 \%$ to $15 \%$ carbohydrate, $5 \%$ to $6 \%$ ash, $4 \%$ to $5 \%$ fiber, and $15 \%$ to $20 \%$ protein. Among the main components, oil has been reported to contain the following components sesamol (SM), sesamolin and sesaminol (4). It has been shown that sesame compounds have many health benefits through increased levels of plasma tocopherol and increased vitamin $\mathrm{E}$ activity, which reduces the mechanisms of aging or malignancy and heart disease (5).

Studies have demonstrated that sesame oil also can repress human colon malignant cell growth in vitro (6), decline blood pressure and increase the antioxidant status in hypertensive patients (7). Mammalian Lignan precursors of sesame seed may have defensive impacts against hormone-related diseases such as breast cancer (8).

Sesame seed components also exert multiple properties on cholesterol metabolism and have lipid-lowering activities (9). Beneficial effects of sesamol on wound healing have been shown in the literature $(10,11)$.

Despite various examinations on sesame and its different uses, there is not adequate information about its impact on the immune system.

This experimental study tried to explore the impacts of sesame seeds oil and sesamol on $\mathrm{T}$ and $\mathrm{B}$ lymphocyte activities as the primary effector cells in cellular and humoral immunity systems. Additionally, the impact of these elements on peritoneal macrophages and dendritic cells as vital arms of the natural immune system were explored.

\section{Methods \\ Study design}

This experimental study was done on spleen cells of mice in vitro. This study possessed one study group and 8-10 weeks old female or male Balb/c mice were recruited.

\section{Samples and preparation of essential oil extract}

The seeds of sesame (Sesamum indicum L.) were collected from the plants cultivated in the Centre of Medicinal Plants Research, in the north of Tehran, Iran, and confirmed by the Centre of Agricultural Research, Tehran, Iran.

For the preparation of essential oil, dried, powdered seeds of sesame $(50 \mathrm{~g})$ were mixed with water on a shaker for 1 hour, after which located in a clevenger distillation apparatus with 1 liter of distilled water and hydro distilled for 3 hours (hydro distillation approach) (12). The oil was then removed and saved at $4{ }^{\circ} \mathrm{C}$ till use.

Sesamol [3, 4-methylenedioxyphenol] (98\% purity) was purchased from Sigma Aldrich company (Cat no: S3003. Sigma, USA).

\section{Animals}

In this examination, 8-10 weeks old male Balb/c mice with $21.4 \pm 0.86$ weight were acquired from the Pasteur Institute of Iran, (Tehran, Iran). They were kept in the animal house of Tarbiat Modares University and given standard mouse chow sterilized water all through the investigation. The strategies were performed by the Guide for the Care and Use of Laboratory Animals.

\section{Isolation and treatment of mouse splenocytes}

Balb/c mice spleens were aseptically removed. Subsequent to mincing utilizing a pair of scissors, the spleen tissues were homogenized in RPMI-1640 (Gibco, USA) by a homogenizer and then placed in a fine steel mesh to get a homogeneous cell suspension. The red blood cells were osmotically lysed with $0.75 \% \mathrm{NH} 4 \mathrm{Cl}$ in Tris cushion $(0.02 \%, \mathrm{pH}=7.2)$. The Lysate was centrifuged $(360$ $\times \mathrm{g}$ at $4{ }^{\circ} \mathrm{C}$ for $\left.10 \mathrm{~min}\right)$ and cell pellet washed three times with phosphate- buffered saline (PBS) and resuspended in RPMI-1640 complete medium supplemented with 11 milli mollar sodium bicarbonate, 2 milli mollar L-glutamine, 100 $\mathrm{U} / \mathrm{ml}$ penicillin, $100 \mu \mathrm{g} / \mathrm{ml}$ streptomycin, and $10 \%$ fetal bovine serum.

\section{Splenocyte disengagement and treatment}

Using trypan-blue staining and counting, cell viability was more than $95 \%$. Splenocyte treatment and proliferation was assayed as follows: $5 \times 10^{6}$ cell $/ \mathrm{ml}$ of the splenocytes seeded into each well of a 96-well flat-bottom plate (Nunc, Denmark) in complete medium. Then phytohaemagglutinin (final concentration $5 \mu \mathrm{g} / \mathrm{ml}$ ), or lipopolysaccharide (final concentration $10 \mu \mathrm{g} / \mathrm{ml}$ ) or PBS Sesame components (final concentration $0.01-100.0 \mu \mathrm{g} / \mathrm{ml}$ ) were added giving a final volume of $200 \mu \mathrm{l}$ (tetraplicate wells). The obtained mixture was incubated for 40 hours at $37{ }^{\circ} \mathrm{C}$ and $5 \% \mathrm{CO}_{2}$ and then MTT [3-(4, 5-Dimethylthiazol-2-yl)-2, 5Diphenyltetrazolium Bromide] assay was performed.

\section{MTT reduction assay}

MTT [3-(4, 5-Dimethylthiazol-2-yl)-2, 5Diphenyltetrazolium Bromide] reduction assay is widely used to evaluate viable cells. MTT reduction is interpreted to be indicative of cellular metabolic activity (12). Briefly, after 48 hours of simulation, MTT ( $5 \mathrm{mg} / \mathrm{ml}$ in PBS) in onetenth of total volume was added to the wells and incubated for 4 hours at $37^{\circ} \mathrm{C}$ under $5 \% \mathrm{CO} 2$. Then supernatants were gently removed and $100 \mu \mathrm{l}$ of acidic isopropanol (0.04 M $\mathrm{HCl}$ in isopropanol) was added in order to dissolve the formazan crystals generated by MTT reduction caused by living cells. Absorbance was read at $540 \mathrm{~nm}$ and result expressed as stimulation Index (SI), which was OD540 of the test samples/OD540 negative control.

\section{Macrophage culture and stimulation}

Macrophages were harvested by the lavage of the peritoneal cavity with $10 \mathrm{ml}$ of RPMI-1640 (Sigma, USA) from BALB/c mice. The cells were centrifuged at $200 \times \mathrm{g}$ and washed. Then cell suspension was adjusted to $1.5 \times 10^{6}$ cells/ml in RPMI-1640 (supplemented with $11 \mathrm{mM}$ sodium bicarbonate, $2 \mathrm{mM}$ L-glutamine, $100 \mathrm{U} / \mathrm{ml}$ penicillin, 100 $\mu \mathrm{g} / \mathrm{ml}$ streptomycin and $5 \%$ fetal bovine serum). The $3 \times 10^{5}$ cell suspensions were seeded $(200 \mu \mathrm{l} /$ well $)$ in 96 -well flatbottomed plates (Nunc, Denmark) and then incubated for 4 hours to adhere in a humidified atmosphere under $5 \% \mathrm{CO}_{2}$ at $37^{\circ} \mathrm{C}$. The non-adherent cells were removed by washing the wells with PBS three times and adherent cells contained 
macrophages incubated for 48 hours more in RPMI medium. To stimulate growth, different concentrations of sesame components $(0.01-100 \mu \mathrm{g} / \mathrm{ml})$ were added to the cells, with a final volume of $200 \mu \mathrm{l}$ in triplicated wells and incubated for 40 hours at $37^{\circ} \mathrm{C}$ under $5 \% \quad \mathrm{CO}_{2}$. Dexamethasone $(10 \mu \mathrm{g} / \mathrm{ml}$, final concentration) and LPSlipopolysaccharide $(10 \mu \mathrm{g} / \mathrm{ml}$, final concentration) were used as controls. After incubation, the treated macrophages were assayed for viability, nitric oxide production, and cytokine release.

\section{Measurement of Nitrite concentration}

Measurement of nitrite concentration was done using the Griess Reaction Assay (13) . Nitrite oxide (NO) released into the supernatants of cultured macrophages and is unstable and rapidly converts to nitrite and nitrate. Detection of nitrite amount as an estimation of NO level synthesis in the cultures was determined by the standard Griess reagent $[1 \%$ sulfanilamide/0.1\% N-(1-naphthyl) ethylenediamine dihydrochloride/2.5\% H3PO4] (Merck). In brief, $50 \mu \mathrm{l}$ of test solution (supernatants of macrophage culture) mixed with $50 \mu \mathrm{L}$ of Griess reagent in a 96-well flat-bottomed plate in triplicate order. After $15 \mathrm{~min}$, absorbance was measured in a Multiskan MS microplate reader at $540 \mathrm{~nm}$. Nitrite concentration was determined from a standard curve of sodium nitrite (14).

\section{Generation of DCs and treatment}

Bone marrow cells obtained from the femur and tibia of female Balb/c mice, and red blood cells were removed by ammonium chloride lysis buffer. Following PBS wash, cells were cultured in RPMI-1640 plus $10 \%$ FCS, $20 \mathrm{ng} / \mathrm{ml}$ GM-CSF, and $10 \mathrm{ng} / \mathrm{ml}$ IL-4. On the second day, $1.5 \times 10^{6}$ cells $/ \mathrm{ml}$ were adjusted to $1.5 \times 10^{6}$ cells $/ \mathrm{ml}$ in RPMI- 1640 complete medium and exposed to sesame components the same as described method for macrophages while DCs were stimulated with LPS $(5 \mu \mathrm{g} / \mathrm{ml})$. After 24 hours, dendritic cells maturation markers and released cytokines were measured.

\section{Evaluation of dendritic cells maturation markers}

DCs phenotypes were determined using FACS analysis system. PE-conjugated mAbs against CD40, CD86, MHCII and PE Cy5-conjugated anti-CD11c were implemented (eBiosciences, USA). The isotype-matched control mAbs were also used.

\section{Cytokine Production by DCs and macrophages}

Supernatants of manipulated DCs and macrophages' culture were collected for measurement of TNF- $\alpha$, IL- $1 \beta$ by ELISA kits (eBiosciences, USA) according to manufacturer's instructions. All samples were measured at least in duplicates. The sensitivity of the TNF- $\alpha$ and IL-1 $\beta$ kits were, 3.7 page TNF- $\alpha / \mathrm{ml}$ and $1.2 \mathrm{pg}$ IL- $1 \beta / \mathrm{ml}$, respectively.

\section{Ethical statement}

The study protocol was approved by Tarbiat Modares University Committee for Animal Studies and all mice fed and kept in standard condition until sacrificed without pain by $\mathrm{CO}_{2}$.

\section{Statistical Analysis}

Statistical analysis was performed using SPSS 15 for Windows software (IBM Corporation, NY, USA). The descriptive information was expressed by mean \pm standard deviation (SD). For multiple comparisons, data analyzed by one-way analysis of variance (ANOVA) and given that the null hypothesis was rejected, then the post hoc comparisons conducted followed by LSD test. The p-values less than 0.05 were considered significant for differences.

\section{Results}

The effect of sesame seed components on mitogenstimulated splenocyte proliferation in vitro and cytokine release

The effects of sesame seeds essential oil and sesamol on the proliferation of mitogen-stimulated splenocyte in vitro and IFN- $\gamma$ and IL-4 release are shown in Fig. 1. The proliferation of splenocytes in 1,10 and $100 \mu \mathrm{g} / \mathrm{ml}$ of sesame essential oil-treated groups were decreased in PHAstimulated with high dose $(100 \mu \mathrm{g} / \mathrm{ml})$ of sesame essential oil series compared to untreated (PBS) splenocytes ( $p=0.011$ splenocytes without mitogen; and $p=0.004$ PHA stimulated splenocytes). In the same pattern sesamol also inhibited proliferation of PHA-stimulated as well as sesame essential oil-treated splenocytes (concentrations of 1-100 $\mu \mathrm{g} / \mathrm{ml})(\mathrm{p}<0.05)$. In case of LPS-stimulated splenocytes, neither sesame oil nor sesamol did not show significant effect on the proliferation of the cells in comparison to PBS-treated splenocytes $(p>0.05)$. Analysis of cytokine release (Fig. $1 \mathrm{C}$ and D) demonstrated that both sesame essential oil and sesamol could suppress production of IFN$\gamma$ form splenocytes $(p<0.05)$ and additionally, sesamol induce secretion of IL-4 from the cells $(p>0.05)$.

The effect of sesame seeds oil and sesamol on macrophage viability, nitric oxide production, and cytokine release

Results for the effects of sesame components on viability, nitric oxide and cytokine release from macrophages are shown in Fig. 2 A-D. In all examined concentrations of sesame essential oil and sesamol, the macrophages showed the same viability as their controls ( $\mathrm{p}=0.764$ for sesame oil and $p=0.642$ for sesamol). In the case of NO production, both components caused inhibition of NO release, while the effect of sesamol was more predominant in these patterns $(p<0.05)$. The effect of sesame components on TNF- $\alpha$ and IL-1 $\beta$ release also were shown as suppression of their products although these effects started to be statistically significant when used with higher concentration (1-100 $\mu \mathrm{g} / \mathrm{ml})(\mathrm{p}<0.05)$. Effects of LPS (as a positive control) in stimulation of macrophages and dexamethasone (as a negative control) in the suppression of macrophage functions were demonstrated as predicted $(p<0.05)$. 

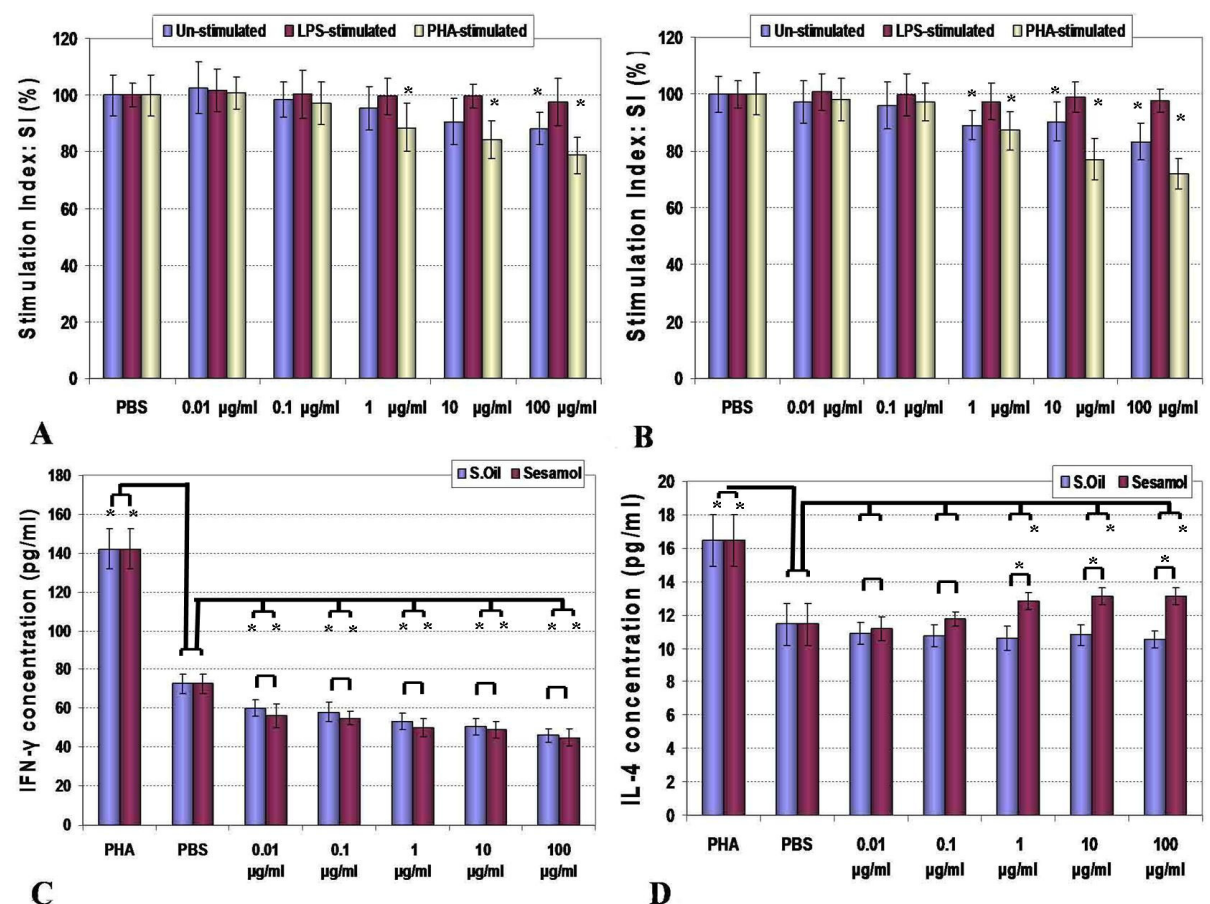

Fig. 1. Effect of sesame seeds essential oil and sesamol $(0.01-100 \mu \mathrm{g} / \mathrm{ml})$ on the proliferation of mitogen-stimulated splenocyte in vitro are shown. Top graphs demonstrate sesame oil (A) and sesamol (B) effects on T cells (PHA stimulated) or B cells (LPS stimulated) proliferation. Effect of sesame oil (C) and sesamol (D) on splenocytes IFN- $\gamma$ and IL-4 release are demonstrated in lower graphs. The values are presented as mean \pm SD. Significant differences were designated as $*(\mathrm{p}<0.05)$.


Fig. 2. Effect of sesame oil and sesamol on viability (A), nitric oxide production (B) and TNF- $\alpha$ (C) and IL-1 $\beta$ (D) release from peritoneal macrophages are shown. Macrophages viability in all groups were the same in MTT reduction assay $(\mathrm{P}>0.05)(\mathrm{A})$. NO release was suppressed by all examined concentrations of sesamol and high doses of sesame oil $(\mathrm{p}<0.05)(\mathrm{B})$. In higher concentrations, sesame oil and sesamol both suppressed the release of TNF- $\alpha(C)$ and IL-1 $\beta$ (D) from macrophages $(p<0.05)$. Significant differences were designated as $*(p<0.05)$.

The effect of sesame seeds essential oil and sesamol on dendritic cells maturation markers

Dendritic cell phenotypes (CD40, CD86, and MHC-II) changes when exposed to the sesame components are shown in Fig. 3. Sesame essential oil and sesamol both prevented induction of mature phenotype of dendritic cells by LPS (demonstrated as a percentage of marker expression and intensity of marker expression by the cells as Mean Fluorescent Intensity: MFI). Enhancement of CD40, CD86, and MHC-II expression by LPS and their suppression by 


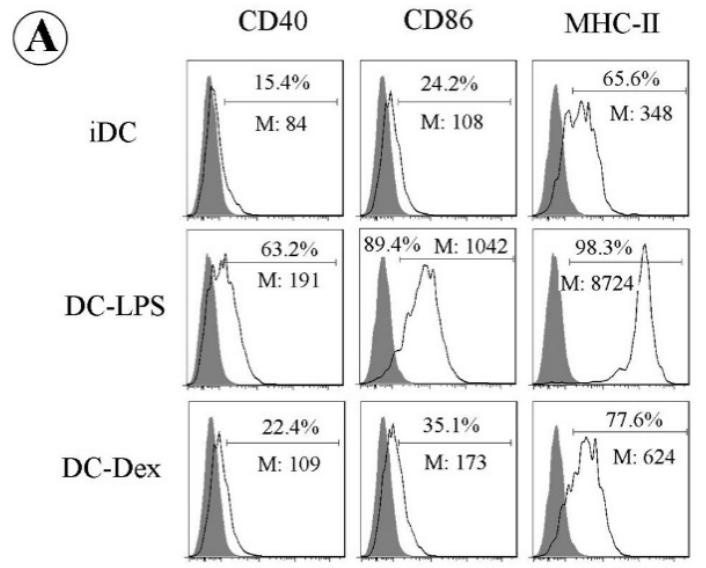

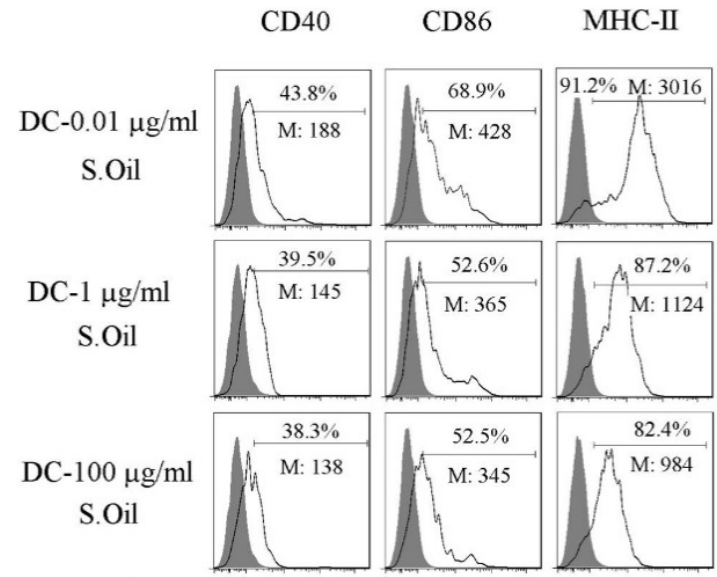

(B)



(C)

Fig. 3. Dendritic cells maturation markers exposed to sesame oil or sesamol are shown. Enhancement of maturation markers expression by LPS and suppression of these molecules expression by Dex are accompanied with prediction as controls (A). DCs exposed to sesame oil (B) and sesamol (C) showed a semi-mature phenotype in comparison with positive and negative maturation marker stimulators.

dexamethasone were as hypothesized $(\mathrm{p}<0.05)$.

The effect of sesame seeds oil and sesamol on TNF- $\alpha$ and IL-16 release by dendritic cells

The results of sesame components effect on bone marrow-derived dendritic cells are shown in Fig. 4. Analysis of the results indicated that both sesame essential oil and sesamol could suppress production of TNF- $\alpha$ in 1$100 \mu \mathrm{g} / \mathrm{ml}$ of concentration and this impact was stronger in case of sesamol $(p<0.05)$. In case of IL-1 $\beta$, sesamol suppressed cytokine release from dendritic cells $(0.1-100$ $\mu \mathrm{g} / \mathrm{ml})$ but sesame oil only in a high dose $(100 \mu \mathrm{g} / \mathrm{ml})$ inhibited cytokine release $(\mathrm{p}<0.05)$. The stimulatory effect of positive control (LPS) and suppressor effect on negative control (dexamethasone) was also shown as predicted $(\mathrm{p}<0.05)$.

\section{Discussion}

In this study, we evaluated the effect of sesame seeds essential oil and sesamol effective component on PHAstimulated splenocytes for T cells and LPS stimulated for B cell analysis as the main effector cells in adaptive immune systems and after that lymphocytes cytokine release. Our results showed that higher examined doses of sesame oil or sesamol have a modulatory effect on PHA stimulated lymphocytes that serve as T lymphocytes.

Sesame (Sesamum indicum L.) a member of the Pedaliaceae family is well-known with derivatives from its seeds. Sesame seeds are rich in oil (high levels of unsaturated fatty acids, primarily oleic and linoleic), protein (especially significant is the limiting amino acid methionine), dietary fiber, and micronutrients such as minerals, lignans, tocopherol, and phytosterol.

It has been shown that these compounds exert many health benefits, confer outstanding resistance to oxidation, may also have anticancer activity, and depress blood pressure and cholesterol levels. Conversely, reported sesame seeds have allergenic effects and can cause adverse effects in susceptible individuals (3).

Sesame seed might induce allergenic symptoms such as urticaria/angioedema, allergic rhinitis, asthma, and even anaphylaxis that show a direct effect of its components on immune responses $(3,15)$. Sesame seed generally 

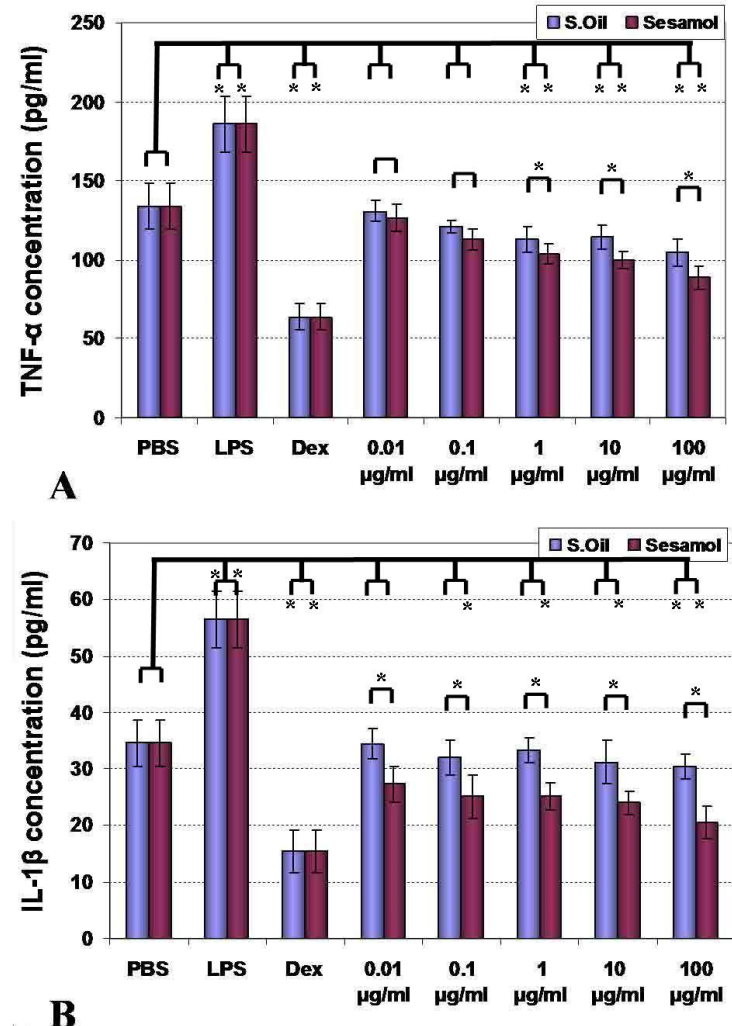

Fig. 4. Effect of sesame oil and sesamol on TNF- $\alpha$ (A) and IL-1 $\beta$ (B) cytokines release are demonstrated. Significant differences were designated as $*(\mathrm{P}<0.05)$.

considered to be devoid of undesirable pigments or offflavors and antitrypsin compounds. Its meal protein is composed of globulins $(67.3 \%)$, albumins $(8.6 \%)$, prolamine $(1.4 \%)$, and glutelin $(7 \%)$.

Sesame protein is high in methionine $(3.2 \%)$, which is unusual for most plant proteins (16). Sesame oil is mainly extracted by pressing and other conventional methods and are rich in fatty acids as Palmitic acid (C16:0; 7-12\%), Palmitoleic acid (C16:1; 0.001-0.5\%), Stearic acid (C18:0; 3.5-6\%), Oleic acid (C18:1; 35-50\%), Linoleic acid (C18:2; 35-50\%), Linolenic acid (C18:3;0.001-1\%) and Eicosenoic acid $(\mathrm{C} 20: 1 ; 0.001-1 \%)$ and moreover aqueous extraction process (AEP) has been considered as a good option for simultaneous extraction of oil and protein (17).

Hence, the observed lower proliferation rates of unstimulated lymphocytes may be due to reduced $\mathrm{T}$ cell subtype while B cells (LPS stimulated) proliferation was not affected. Thus, in general, we could propose that sesame essential oil and sesame could modulate the $T$ cell immune responses known as cellular immune responses while humeral responses are unaffected. On the other hand, these components shifted lymphocytes cytokine release toward Th2 responses (lower IFN- $\gamma$ and higher IL-4). These data may explain the beneficial traditional application of sesame essential oil for diabetes (18), autoimmune (11) and inflammatory diseases (19).

Observed induced T cells modulations and Th2 cytokines shift also are accompanied with previously reported effects of sesame seeds in the induction of allergenic symptoms such as urticaria/angioedema, allergic rhinitis, asthma and anaphylaxis $(3,15)$. We also examined the cytotoxic effect of sesame extracts on peritoneal macrophages. The results of viability assay showed that both extracts did not have any significant cytotoxic effect on macrophages.

NO production and TNF- $\alpha$ and IL- $1 \beta$ cytokine release were suppressed by these sesame components. These findings indicated that sesame ingredients exhibit antioxidant and anti-inflammatory activities. In the case of macrophages, a study demonstrated that ethanol extract of sesame coat could inhibit inducible nitric oxide synthase (iNOS) production and also prevention of LPS-induced $\mathrm{NF} \kappa \mathrm{B}$ activation in activated macrophages (20). Latif et al showed that Aqueous extracts of sesame seeds had a high amount of tocopherols and an appreciable increase in the antioxidant activity was assessed by determinations of total phenolic contents, DPPH radical scavenging capacity, and inhibition of linoleic acid oxidation were also shown (21).

Oral administration of sesame oil has been shown to reduce iron-induced lipid peroxidation and lipopolysaccharide-stimulated proinflammatory cytokine production in rats $(22,23)$. In this respect, a study on olive oil has demonstrated that enzymatic treatment during aqueous extraction enhanced the release of minor components such as phenols, tocopherols etc., into the oil, thus contributing to the superior antioxidant attributes to such oils (24). In the other hand, sesamol (3,4methylenedioxyphenol) is a phenolic derivative of sesame oil with a methylenedioxy compound that could play appropriate functions as an antioxidant (25).

In the other in vivo study, anti-oxidant activities of sesamol were shown in intraperitoneal (I.P.) administration (26). In another report, sesamol attenuates systemic LPSinduced lung inflammation by inhibiting the alveolar macrophage inflammatory response in rats (27).

In the third part of this study, we examined the effect of sesame oil and sesamol on dendritic cells. Results indicated inhibitory functions of sesame components of DCs maturation and also suppression of TNF- $\alpha$ and IL-1 $\beta$ cytokine release. Although there is not a distinct study on the effect of sesame components on DCs, we could seek for some evidence. As we mentioned above sesame oil has been reported to exhibit antioxidant and anti-inflammatory effects. A study also reported that sesamol by preventing the oxidative degradation of collagen fibers gives the required strength to the scars of wounds, improve wound healing; phenomena that incorporate pro-inflammatory responses (10). Another study has shown that sesamol has a protective effect in nonsteroidal anti-inflammatory druginduced gastric ulcer (28). The author of this manuscript has demonstrated that sesamol attenuate the recruitment of inflammatory cells, mast cells, CD68(+) Kupffer cells, and neutrophils in hepatic injuries (29). Hsu et al showed that sesamol significantly reduces the gastric ulceration and hemorrhage and inhibit mucosal TNF- $\alpha$, IL-1 $\beta$, and IL-6 production and $\mathrm{NF}-\kappa \mathrm{B}$ activity in stress-related mucosal disease in rats (30). Hence, all of these studies confirm our findings on anti-inflammatory effects of sesame seed components. 


\section{Conclusion}

We showed the immunomodulatory effects of sesame seeds essential oil and sesamol as an effective component of sesame seed by suppression of PHA-activated splenocytes considered as $\mathrm{T}$ cells and Th2 cytokine shift. Both examined components might suppress NO production and cytokine release from macrophages, or modulate the function and phenotype of the dendritic cells by preventing the induction of DCs mature phenotypes and suppression of pro-inflammatory cytokine release. Further specific studies on the immune system by in vivo tests and analysis of other sesame seed ingredients are essential to clarify more details about its nutrient properties and to find new therapeutic use for it.

\section{Acknowledgments}

This work was supported by grant number 2190 from the Arak University of Medical Sciences.

\section{Conflict of Interests}

The authors declare that they have no competing interests.

\section{References}

1. Moreira DdL, Teixeira SS, Monteiro MHD, De-Oliveira ACAX, Paumgartten FJR. Traditional use and safety of herbal medicines1. Rev Bras Farmacogn. 2014;24(2):248-57.

2. Jantan I, Ahmad W, Bukhari SNA. Plant-derived immunomodulators: an insight on their preclinical evaluation and clinical trials. Front Plant Sci 2015;6:655.

3. Elleuch MBD, Zitoun A. Sesame (Sesamum indicum L.) Seeds in Food, Nutrition, and Health. Nuts and Seeds in Health and Disease Prevention. 2011; Chapter 122:1029-36.

4. Jeong SM, Kim SY, Kim DR, Nam K, Ahn D, Lee SC. Effect of seed roasting conditions on the antioxidant activity of defatted sesame meal extracts. J Food Sci. 2004;69(5):C377C81.

5. Cooney RV, Franke AA, Wilkens LR, Gill J, Kolonel LN. Elevated plasma $\gamma$-tocopherol and decreased $\alpha$-tocopherol in men are associated with inflammatory markers and decreased plasma 25-OH vitamin D. Nutr cancer. 2008;60(Suppl 1):21-9.

6. Majdalawieh AF, Massri M, Nasrallah GK. A comprehensive review on the anti-cancer properties and mechanisms of action of sesamin, a lignan in sesame seeds (Sesamum indicum). Eur J Pharmacol. 2017;815:512-21.

7. Hsu E, Parthasarathy S. Anti-inflammatory and Antioxidant Effects of Sesame Oil on Atherosclerosis: A Descriptive Literature Review. Cureus. 2017;9(7):e1438.

8. Harikumar KB, Sung B, Tharakan ST, Pandey MK, Joy B, Guha S, et al. Sesamin manifests chemopreventive effects through the suppression of NF-kappa B-regulated cell survival, proliferation, invasion, and angiogenic gene products. Mol Cancer Res. 2010;8(5):751-61.

9. Visavadiya NP, Narasimhacharya AV. Sesame as a hypocholesteraemic and antioxidant dietary component. Food and chemical toxicology: Food Chem Toxicol. 2008;46(6): 1889-95.

10. Shenoy RR, Sudheendra AT, Nayak PG, Paul P, Kutty NG, Rao CM. Normal and delayed wound healing is improved by sesamol, an active constituent of Sesamum indicum (L.) in albino rats. J Ethnopharmacol. 2011;133(2):608-12.

11. Ghazavi A, Mosayebi G. The mechanism of sesame oil in ameliorating experimental autoimmune encephalomyelitis in
C57BL/6 mice. Phytother Res. 2012;26(1):34-8.

12. Sladowski D, Steer SJ, Clothier RH, Balls M. An improved MTT assay. J Immunol Methods 1993;157(1-2):203-7.

13. Granger DL, Taintor RR, Boockvar KS, Hibbs JB. Measurement of nitrate and nitrite in biological samples using nitrate reductase and Griess reaction. Methods Enzymol. 268: Academic Press; 1996. p. 142-51.

14. Scuro LS, Simioni PU, Grabriel DL, Saviani EE, Modolo LV, Tamashiro WM, et al. Suppression of nitric oxide production in mouse macrophages by soybean flavonoids accumulated in response to nitroprusside and fungal elicitation. BMC Biochem. 2004;5:5.

15. Cohen A, Goldberg M, Levy B, Leshno M, Katz Y. Sesame food allergy and sensitization in children: the natural history and long-term follow-up. Pediatric allergy and immunology: Pediatr Allergy Immunol. 2007;18(3):217-23.

16. Inyang $\mathrm{U}$ E, Iduh $\mathrm{A}$. O. Influence of $\mathrm{pH}$ and salt concentration on protein solubility, emulsifying and foaming properties of sesame protein concentrate. J Am Oil Chem Soc. 1996;73:1663-7.

17. Orsavova J, Misurcova L, Vavra Ambrozova J, Vicha R, Mlcek J. Fatty Acids Composition of Vegetable Oils and Its Contribution to Dietary Energy Intake and Dependence of Cardiovascular Mortality on Dietary Intake of Fatty Acids. Int J Mol Sci. 2015;16(6):12871-90.

18. Sankar D, Ali A, Sambandam G, Rao R. Sesame oil exhibits synergistic effect with anti-diabetic medication in patients with type 2 diabetes mellitus. J Clin Nutr. 2011;30(3):351-8.

19. Namiki M. Nutraceutical functions of sesame: a review. Crit. Rev. Food Sci Nutr. 2007;47(7):651-73.

20. Wang BS, Chang LW, Yen WJ, Duh PD. Antioxidative effect of sesame coat on LDL oxidation and oxidative stress in macrophages. Food Chem. 2007;102(1):351-60.

21. Latif S, Anwar F. Aqueous enzymatic sesame oil and protein extraction. Food Chem. 2011;125(2):679-84.

22. Hemalatha S, Raghunath M. Dietary sesame (Sesamum indicum cultivar Linn) oil inhibits iron-induced oxidative stress in rats. Br J Nutr. 2004;92(04):581-7.

23. Hsu DZ, Su SB, Chien SP, Chiang PJ, Li YH, Lo YJ, et al Effect of sesame oil on oxidative-stress-associated renal injury in endotoxemic rats: involvement of nitric oxide and proinflammatory cytokines. Shock. 2005;24(3):276-80.

24. Ranalli A, Malfatti A, Lucera L, Contento S, Sotiriou E. Effects of processing techniques on the natural colourings and the other functional constituents in virgin olive oil. Food Res Int.2005;38(8):873-8.

25. Hsu DZ, Li YH, Chu PY, Chien SP, Chuang YC, Liu MY. Attenuation of endotoxin-induced oxidative stress and multiple organ injury by 3, 4-methylenedioxyphenol in rats. Shock. 2006;25(3):300-5.

26. Parihar VK, Prabhakar K, Veerapur VP, Kumar MS, Reddy YR, Joshi R, et al. Effect of sesamol on radiation-induced cytotoxicity in Swiss albino mice. Mutat Res Genet Toxicol Environ Mutagen. 2006;611(1):9-16.

27. Chu PY, Chien SP, Hsu DZ, Liu MY. Protective effect of sesamol on the pulmonary inflammatory response and lung injury in endotoxemic rats. Food Chem Toxicol. 2010;48(7):1821-6.

28. Hsu DZ, Chu PY, Li YH, Liu MY. Sesamol attenuates diclofenac-induced acute gastric mucosal injury via its cyclooxygenase-independent antioxidative effect in rats. Shock. 2008;30(4):456-62.

29. Periasamy S, Hsu DZ, Chen SY, Yang SS, Chandrasekaran VRM, Liu MY. Therapeutic sesamol attenuates monocrotalineinduced sinusoidal obstruction syndrome in rats by inhibiting matrix metalloproteinase-9. Cell Biochem Biophys. 
Effect of sesame oil on Immune system

2011;61(2):327-36

30. Hsu DZ, Chen YW, Chu PY, Periasamy S, Liu MY.

Protective effect of 3, 4-methylenedioxyphenol (sesamol) on stress-related mucosal disease in rats.. Biomed Res Int. 2013;2013. 